\title{
A SUPPLIER RISK MATRIX APPROACH TO ISO 9001:2015 COMPLIANCE: A CASE STUDY
}

Lisa M. Walters

The BRC Academy Journal of Business 10, no. 1 (2019): 65-81.

http://dx.doi.org/10.15239/j.brcacadjb.2020.10.02.ja03

WEB APPENDIX

https://dx.doi.org/10.15239/j.brcacadjb.2020.10.01.wa03

\begin{tabular}{|l|l|l|l|l|}
\hline $\begin{array}{l}\text { Product/Service } \\
\text { Implication: }\end{array}$ & $\begin{array}{l}\text { Negligible } \\
\text { No critical } \\
\text { implications }\end{array}$ & $\begin{array}{l}\text { Minor } \\
\text { One critical } \\
\text { implication } \\
\text { Hisplier }\end{array}$ & $\begin{array}{l}\text { Major } \\
\text { Two critical } \\
\text { implications }\end{array}$ & $\begin{array}{l}\text { Critical } \\
\text { Three critical } \\
\text { implications }\end{array}$ \\
\hline Unknown & & & \\
\hline $\begin{array}{l}\text { Done business, } \\
\text { but limited data }\end{array}$ & & & & \\
\hline $\begin{array}{l}\text { Established, but } \\
\text { occasional to } \\
\text { frequent } \\
\text { Corrective } \\
\text { Action Requests } \\
\text { for period under } \\
\text { review. }\end{array}$ & & & & \\
\hline $\begin{array}{l}\text { Established with } \\
\text { few to no } \\
\text { problems for } \\
\text { period under } \\
\text { review. }\end{array}$ & & & & \\
\hline
\end{tabular}

Figure 1: Foundation of Supplier Risk Matrix 
Figure 2: Completed Supplier Risk Matrix

\begin{tabular}{|c|c|c|c|c|}
\hline $\begin{array}{l}\text { Product/Service } \\
\text { Implication: } \\
\text { Supplier } \\
\text { History: }\end{array}$ & $\begin{array}{l}\text { Negligible } \\
\text { No critical } \\
\text { implications }\end{array}$ & \begin{tabular}{|l|} 
Minor \\
One critical \\
implication
\end{tabular} & $\begin{array}{l}\text { Major } \\
\text { Two critical } \\
\text { implications }\end{array}$ & $\begin{array}{l}\text { Critical } \\
\text { Three critical } \\
\text { implications }\end{array}$ \\
\hline Unknown & 5 & 9 & 13 & 16 \\
\hline $\begin{array}{l}\text { Done business, } \\
\text { but limited data }\end{array}$ & 4 & 8 & 12 & 15 \\
\hline $\begin{array}{l}\text { Established, but } \\
\text { occasional to } \\
\text { frequent } \\
\text { Corrective } \\
\text { Action Requests } \\
\text { for period under } \\
\text { review. }\end{array}$ & 2 & 7 & 11 & 14 \\
\hline $\begin{array}{l}\text { Established with } \\
\text { few to no } \\
\text { problems for } \\
\text { period under } \\
\text { review. }\end{array}$ & 1 & 3 & 6 & 10 \\
\hline
\end{tabular}


Figure 3: Risk Level Criticality for Existing Suppliers

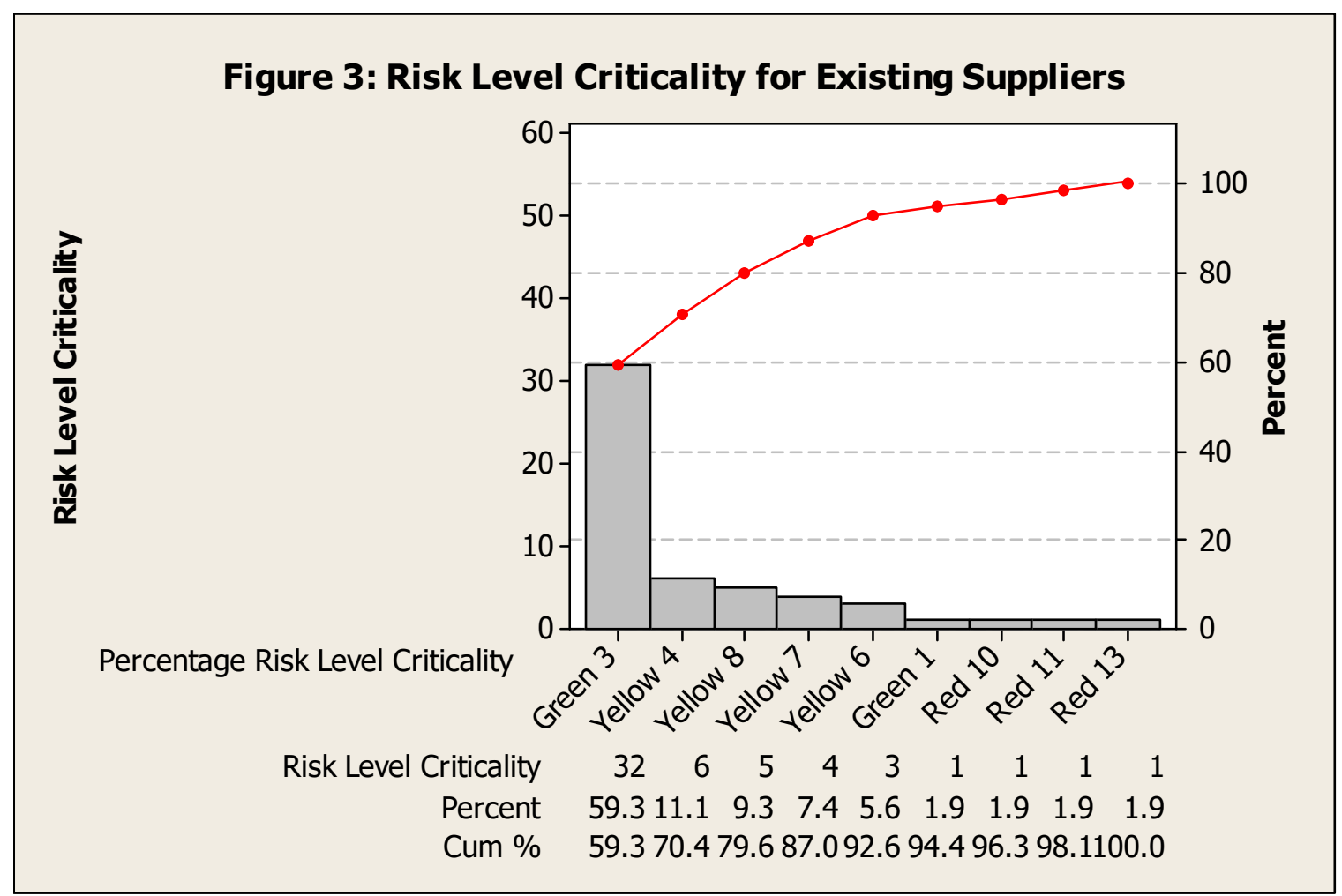

